\title{
Specific Issues and Challenges in Translating EU Law Texts
}

\author{
By Ljubica Kordić
}

\begin{abstract}
In the contemporary world of globalization and international collaboration in all spheres of human life, the English language has become a lingua franca of international communication. Along with French and German, English is one of three working languages of the EU Commission and the most commonly used language among lawyers and judges of the EU courts in their everyday professional communication. Based on one of the essential principles of the Union - the principle of equality of member states and the languages spoken in them - all legal documents of the EU are drafted in the three working languages and translated into the languages of other Member States simultaneously. As the European legal system is usually qualified as a "hybrid" system comprising the elements of both the common law system and the civil law system, new legal concepts and terms have been introduced, which may cause problems in translation. In this paper, the author explores the features of legal English with specific reference to the language of the EU law by addressing the problems and challenges that translators face with when dealing with legal texts. In the introductory part of the paper, the author offers an overview of existing theoretical approaches to legal translation. The emphasis is placed on the functionalist approach which observes translation from a socio-cultural perspective and determines the function of the text in the target language, the target culture, and the recipient of the translation as essential factors of specialized translation. In the main part of the paper, linguistic features of the language of law are analysed and discussed from the point of view of translation problems and challenges. The comparative approach is used in analysing legal terms and phrases with specific reference to linguistic and cultural differences in the English and German languages of law and their corresponding functional equivalents in the Croatian language. The author also addresses the problem of newly coined words or wrongly used words of the English language that have become a part of the EU law terminology and may lead to misunderstandings and wrong translations.
\end{abstract}

\section{Introduction}

The aim of this paper is to present problems and challenges that translators of legal texts are faced with. In the first part, the theoretical background of legal translation is presented, with special emphasis of the functionalist approach to translation, developed in the 1970s by German translation school. This approach is highly recommended as the most appropriate approach in legal translation, who argues that the law has always been strongly determined by the culture and the legal system it derives from. The main part of the paper deals with the most

*Associate Professor, University of Osijek, Croatia. 
striking problems in translating legal texts that might lead to misunderstandings and even produce unwanted consequences for the target receiver of the translation. By means of comparative analysis, specific linguistic phenomena in the English language of law will be discussed that could represent "traps" for an inexperienced translator, and recommendations for solving those translation problems will be offered. Special emphasis will be placed on EU law terminology, particularly the phenomena of newly coined legal terms and the use of plain language words in different meaning in the context of European legislation.

\section{Specific Features and Challenges of Legal Translation}

Translation is "a process in which a translator makes a number of decisions on how to interpret the source text". ${ }^{1}$ These decisions relate to the use of resources and application of specific strategies and techniques with the purpose to reexpress the meaning of the source text in the target language. This is the reason why translation is perceived as a problem-solving process. ${ }^{2}$ Translations of legal texts belong to the oldest written translations ever. Legal documents of Roman law have been translated from Latin into other languages and cultures, and those translations have influenced the linguistic features of legal texts up to modern times. Sources of the problems that legal translators and interpreters are faced with can be observed at the linguistic, morpho-syntactic and stylistic levels. The following section of the paper will be dedicated to linguistic features of legal texts, which may represent challenges and problems for an inexperienced translator.

\section{Complexity and Obscurity of Legal Texts}

Language plays a very important role in law. It is not only a means of expressing legal rules and relations but also represents "the lawyer's most powerful tool". ${ }^{3}$ Due to the fact, that the law regulates all complex aspects of human reality, the language of law (legalese) is inevitably complex and obscure. The problem of understanding the legal texts by lay people as addressees was discussed by many authors dealing with legal linguistics. Lerch puts the obscurity of legal texts in correlation with the written form of laws, arguing that the essential cause of the obscurity of legal texts was the fact that written laws have been introduced into western legal tradition by the Roman law and as such kept

1. Angelo Pizzuto, “Translation Procedures: The Technical Component of the Translation Process", accessed March 25, 2019, https://bit.ly/31E1vJA.

2. Pizzuto, "Translation Procedures".

3. Susan Šarčević, Legal Language in Action: Translation, Terminology, Drafting and Procedural Issues (Zagreb: Globus, 2009), 10. 
many features of the Latin language and the "wordy" style of ancient laws. Due to an attempt of producing precise and exact written texts that would guarantee legal certainty, ancient lawgivers have produced legal texts in such a complex style, that ordinary citizens could hardly understand them. "Legal texts, which for the sake of clarity, precision, and legal certainty have been drafted in written form, hide in themselves the exact opposites of those features, and as such inevitably provoke the differences between the written text and its content". ${ }^{4}$ Commenting the fact that lay people are faced with difficulties in understanding legal texts, Lerch states that there are still many lawyers who believe that it was not necessary for lay people to understand laws because the task of lawyers is to interpret them. ${ }^{5}$ According to Lerch, the obscurity of legal texts originates from the written version of the first legal document of the customary Roman law - the Twelve Tables law. ${ }^{6}$ Although the complexity of legal language is sometimes explained by specific features of the language system, like in the case of the "wordiness" of the German language of law, most linguists attribute the complexity and the obscurity of the language of law to "the abstract character of legal thinking".7

Another cause of the obscurity of the English language of law lies in its foundation on tradition and customary law. Living proof of that are terms that are still used in English law, like the words originating from the Viking conquerors, such as loan, sale, trust, or writ of summons stemming from the time of the Norman invasion. ${ }^{8}$ After 1066, Norman French became the language of English high society, while common people used the English language in their everyday communication. In the following three centuries, French became the language of the judicial procedure, while laws and judicial documents, as well as the documents and the correspondence of public administration were in Latin. After 1356, English was introduced in judicial communication, but all judicial documents and legal acts were written in Latin. In the $15^{\text {th }}$ century up to the year

4. Kent Lerch, Recht verstehen. Verständlichkeit, Missverständlichkeit und Unverständlichkeit von Recht, (Berlin, New York: Walter de Gruyter, 2005), XIX: "Rechtstexte, die um der Klarheit, Bestimmtheit und Rechtssicherheit willen verschriftlicht werden, bergen also gerade das Gegenteil davon in sich, provozieren sie jedoch unvermeidlich eine Differenz von Text und Sinn." (Translated from German by the author of this paper).

5. Lerch, Recht verstehen.

6. Lerch, Recht verstehen, XV: “(...) denn Klagen darüber, dass man das Recht nicht verstehen kann, erreichen uns schon aus dem alten Rom. Sie sind die unausweichliche Konsequenz des Gründungsaktes des römischen Rechts, der Verschriftlichung der Rechtsgewohnheiten in den Zwölf Tafeln." (Translated from German by the author of this paper).

7. Heikke Mattila, Comparative Legal Linguistics (Aldershot: Ashgate Publishing, 2006), 173-175.

8. Mattila, Comparative Legal Linguistics, 225. 
1485, judicial documents and legal acts were written in French. ${ }^{9}$ The impact of these diverse language influences can be well illustrated by the following quotation:

"As the printed word became more commonplace, some writers made a deliberate effort to adopt words derived from Latin, with the aim of making their text appear more sophisticated. Some writers also started to use a Latin word order. This led to an ornate style, deliberately used to impress rather than inform. Even today, Latin grammar is responsible for some of the ornateness and unusual word order of legal documents." 10

English language of law is influenced by other European languages, particularly by German and French. The influence of the customary law of Germanic tribes on English legal tradition is reflected in archaic phrases of binary character (doublets): act and deed, fit and proper, life and limb. Linguistic traces of French are legal terms with suffixes - é (-ee) in a passive meaning and -or for an active person or agent: employee, legatee, trustee vs. employer, trustor, vendor. The nouns with suffixes $-a l$ and -el (denial, proposal, rebuttal, estoppel) are of French origin as well. Accordingly, French word formation is observable in some loaned compounds combined with an adjective in the manner typical of the French language: attorney general, court martial. ${ }^{11}$

Apart from the features discussed above, Tiersma has added rituality and formality of expression as well as redundancy and "wordiness" as typical features of legal style contributing to the complexity and obscurity of legal texts. ${ }^{12}$

\section{Cultural Dimension of Legal Texts}

Translation in the field of law is a complex and demanding procedure. The translator is faced with serious challenges because legal translation needs to be accurate and transpose the same ideas expressed in the source text. The translated text should always have the same legal effect as the source text and may address serious political and international issues, so that a wrong translation in the field of law "may induce peace or a prompt war". ${ }^{13}$ One of the essential sources of problems in translating legal texts is the fact that the language of the law is inevitably culture-bound. For many esteemed scholars (e.g.

\footnotetext{
9. Rupert Haigh, Legal English (Abingdon/ New York: Routledge-Cavendish, 2004), X.

10. Haigh, Legal English, X.

11. Mattila, Comparative Legal Linguistics, $225 \mathrm{ff}$.

12. Peter M. Tiersma, Legal Language (Chicago, IL: University of Chicago Press, 1999),
} 101.

13. Susan Šarčević, New Approach to Legal Translation (The Hague-London-Boston: Kluwer Law International, 2000), II. 
Duranti, 1997; Bhatia \& Bhatia, 2011) $)^{14}$, the cultural dimension represents one of the crucial factors in the translation and/or interpretation of legal texts. The awareness of the strong impact of culture on legal concepts and their corresponding terms in every legal system has led to crucial changes in the approach to specialist translation in general and particularly to translation in the field of law. Traditional translation by lexical equivalents has turned out to be inadequate in the translation of legal texts, so the new functionalist approach was initiated in the 1980s. By this approach, extra-linguistic factors and the sociocultural context of the target language were for the first time observed as essential translation factors. Katarina Reiss and Hans Vermeer, the representatives of the German translation school and the authors of the Scopos-translation theory, defined legal translation as a cultural transfer from one legal system and one culture into another. ${ }^{15}$ According to the new approach, the target language, target culture, the target user of the translation and the purpose of translation (skopos) are considered as the main factors of the translation process. From the perspective of the functionalist approach, translation equivalents can be understood only as functional equivalents because of cultural differences in the field of law between the source and the target text. Sandrini's term for equivalents in legal translation is relative equivalents ${ }^{16}$, whereas Prunč determines this phenomenon as asymmetry of translation. ${ }^{17}$ Šarčević defined the functional equivalent in the field of law as a term "designating a concept or institution of the target legal system having the same function as a particular concept of the source legal system."18 The example of English legal terms with relative or asymmetrical equivalents in the civil law system is the law of torts. On the other hand, the term from the civil law system prekršajno pravo (Croatian) or Ordnungwidrigkeit (German) does not have its full equivalent term in English legal terminology, so the best solution in this case is coining the nearest functional equivalent petty offence law. These examples illustrate the importance of the knowledge of comparative law, as determined by Zweigert and Kötz ${ }^{19}$ back in 1969 in their comparative law approach.

14. Alessandro Duranti, Linguistic Antropology (Cambridge: Cambridge University Press, 1997); Vijay Kumar, Bhatia, and Aditi Bhatia, "Legal discourse across cultures and socio-pragmatic contexts", World Englishes, 30, no. 4, (2011) 481-495. https://doi.org/10.11 11/j.1467-971X.2011.01735.

15. Katarina Reiss and Hans Vermeer, Grundlegung einer allgemeinen Translationstheorie (Tübingen: Niemeyer, 1984), 13.

16. Peter Sandrini, (Ed) Ubersetzen von Rechtstexten-Fachkommunikation im Spannungsfeld zwischen Rechtsordnung und Sprache (Tübingen: Gunter Narr Verlag, 1999).

17. Erich Prunč, Entwicklungslinien der Translationswissenschaft. Von den Asymmetrien der Sprachen zu den Asymmetrien der Macht (Berlin: Frank \& Timme, 2012).

18. Šarčević, New Approach to Legal Translation, 236.

19. Konrad Zweigert, Hein, Kötz. Einführung in die Rechtsvergleichung/An Introduction to Comparative Law/, 1st ed., 1996. 
Specific Features of Legal Terminology and Legal Style

The law as a system is very complex and comprises many different legal branches regulating all spheres of human reality. Legal terms reflect legal concepts that are different in different legal systems. This implies that the legal translator should master not only the essential knowledge of the source legal system and its terminology but also concepts and terms of the target legal system and keep in mind the essential differences between them. As law regulates all aspects of human life in all its complexity, it encompasses numerous branches with an immense quantity of specific legal concepts and terms. The question of legal terminology includes not only a huge variety of specific legal terms and phrases but also linguistic phenomena that can cause serious problems in translating legal texts. Those are the following phenomena: polysemy of legal terms, synonymy, legal phrases and collocations, phrasal verbs that have lost their essential meaning, archaic terms stemming from other languages, legal doublets and illogical expressions (wrong usage of adjectives).

\section{The Polysemy of Legal Terms}

Polysemy is a phenomenon that could lead to misunderstandings and cause problems in translation. Sandrini distinguishes between external and internal polysemy. External polysemy refers to the same expressions that have a different meaning in the plain language from that in the language of law (challenge, power, bill, party). Internal polysemy occurs within the language of law and refers to differences in meaning between one and the same term in different legal branches of law ${ }^{20}$. Two versions of the term damage: damage vs. damages can serve as an illustration of the term encompassing different meanings within the same branch law: the former term is used in the original meaning of damage, the latter in the meaning 'compensation for the damage suffered'. The equivalents offered in general language dictionaries could easily mislead the translator because the former term is translated in its general meaning, while the latter is either not mentioned or is interpreted as the plural of damage. The wrong translation may cause problems for the target recipient and can produce wrong legal effects.

20. Sandrini, (ed) Ubersetzen von Rechtstexten. 


\section{Synonymy and Antonymy}

Synonymy is a feature of legal texts that can lead to false translation as well. The legal translator should be aware of the fact that in the language of law different terms can be used for the same legal concepts in two different branches of law. Illustrative examples can be a plaintiff in criminal law versus claimant in civil law and petitioner in the EU law, or the synonymous terms sue and prosecutethe former is used in civil procedure, the latter in criminal procedure. Synonymous equivalents of these terms are not observable in the German or Croatian languages of law. If the translator is not aware of these differences, he/she will produce an inaccurate translation into English as the target language. On the other hand, the German language of law differs between the terms Recht and Anspruch - the former denoting law and/or "objective" right to something, while the latter designates a "subjective" entitlement of a person to exercise the specific right(s).

\section{Legal Phrases and Collocations}

Usage of legal phrases and collocations can be a problem in the translation process in two respects. A phrase is defined as a grammatical unit smaller than a clause consisting of two or more words ${ }^{21}$ which differs from other poly-lexical expressions by its structural pattern, semantic relationship between its constituent parts, its terminological distribution and the frequency of its occurrence (e.g. come into force). The term collocation designates "a two-word term, the semantic interdependence of its constituent parts representing its specific linguistic feature" ${ }^{22}$ Within a collocation, a noun is combined with another noun, a verb or an adjective, or it may be a combination of a verb and an adverb. Two words cooccurring in a specific lexical and semantical connection within a collocation can occur separately as well as in other lexical relations. One constituent of the collocation is usually of metaphorical meaning, which might represent a "trap" for a translator, who needs to know the corresponding collocation in the target language/culture. Some English legal collocations (e.g. legal capacity, legal remedy, burden of evidence, natural person) have corresponding functional equivalents with the same metaphoric constituents in the German language of law, though mostly in the form of compounds, due to the specific word formation system of the German language: Rechtsfähigkeit, Rechtsmittel, Beweislast, natürliche Person. However, in most cases, the metaphoric character of legal expressions differs

21. Robert L. Trask, Language and Linguistics: The Key Concepts, New York: Routledge, 2008.

22. Marie-Claud L'Homme and Claudine Bertrand, "Specialized Lexical Combinations: Should they be described as Collocations or in Terms of Selectional Restrictions?" in Proceedings. Ninth Euralex International Congress, Stuttgart: Stuttgart University, 2000), 497506. 
from one language to another, so the translator should be aware of those differences, e.g. break the law, press charges, lodge an appeal (in German: Recht verletzen - literally: to injure law, Klage erheben - literally: to elevate charges, Berufung einlegen - literally: to put in an appeal). Apart from legal phrases and collocations, the language of law is also characterized by structures with phrasal verbs - the verbs which have lost their original meaning when used within those structures (e.g. take, make, give, fulfill in the following legal expressions: take action, make decision, give assistance, pass ruling, etc.). Although some phrasal ('empty') verbs have their literal equivalents in other languages (e.g. English: fulfil duty vs. German: Pflicht erfüllen), most of them usually cannot be literally translated into other languages. This can be well illustrated by the German language structures corresponding with the English phrasal verbs mentioned above: Handlungen vornehmen (literally: undertake actions), Entscheidung treffen (literally: meet decision), Urteil fällen (literally: cut down ruling). ${ }^{23}$

Structures known as legal doublets are also an ingredient part of the English legal phraseology. Doublets or structural stereotypes represent two terms connected by the conjunctions and/or, which are in most cases tautologies or synonymous terms (also called pleonasms), e.g. null and void, law and order, terms and conditions, last will or testament. According to Mattila, ${ }^{24}$ most of them are translations from the German language of law (null und nichtig, Recht und Ordnung, letzter Wille und Testament). In some other languages, e.g. Croatian, those expressions are translated by one word: ništav, pravo, uvjeti, testament. Legal translators should be aware of the frequency of legal doublets in English and know which corresponding structures are used in the target language and/or culture.

\section{The Use of Archaic Terms from Other Languages}

Use of Latin legal terms and archaic loanwords from other languages in the English language of law has already been mentioned in the introduction to this paper (ab initio, in flagrante, writ of summons, ye in the court proceedings, etc.). It is important for the translator to keep in mind those terms, as well as English archaic terms like herewith, therefrom, wherein, whereof, herein, hereby, thereof, which are mostly used in written legal texts and in professional correspondence. Although these terms are not difficult to understand in an original legal document in English, it is of utmost importance for a translator to know when to use these archaic terms in the translation from English into some other language that is not inclined to those terms, for example Croatian. Here is one example

23. Ljubica Kordić. Pravna lingvistika - sinergija jezika i prava/Legal Linguistics - A Synergy of Language and the Law/ (Osijek: Pravni fakultet Osijek, 2015).

24. Mattila, Comparative Legal Linguistics. 
from the USA Constitution: "Taxes are public burdens imposed generally upon the inhabitants of the whole state or upon some civil division thereof" ${ }^{\prime 25}$

\section{Wrong or Illogical Use of Attributes}

Another problem might be the use of adjectives against the rules of English grammar like in the cases attorney general, court-martial. These expressions are built according to the French and Latin word order - the noun is post-modified by an adjective. ${ }^{26}$ The example abroad maintenance regulation can be considered a grammatically deviant structure because the adverb is used in attributive function in front of the noun. This phrase, which is used in International Family Law, is built by omitting the preposition from (regulation of the maintenance from abroad). Interestingly, the German language of the law is also inclined to using wrongly attributed nouns, but of quite a different structure than in English due to the specific word formation rules in German. ${ }^{27}$ Usually, a compound noun is attributed by an adjective, but instead of attributing the second constituent of the compound functioning as the basic constituent, in these cases adjectives falsely refer to the first constituent: bewaffneter Diebstahl (instead of bewaffneter Dieb). Interestingly, the corresponding term in English is armed robbery, which is also against logic, as the adjective armed, which is usually attached to living beings, is used to denote an offence by use of weaponry. These expressions in both languages have been accepted as a part of legal phraseology, so their semantic accuracy is not questioned any more. If the translator is not familiar with the cases of breaking grammar rules, he/she can easily misinterpret the meaning and translate such expressions wrongly.

\section{The Frequency of Specific Grammar Structures}

Legal language is also inclined to the frequent use of specific grammar structures. Inexperienced translators, who are prone to rely solely on the standard grammar rules on tenses in English, are usually not familiar with the fact that the structure shall + infinitive is frequently used in English laws and tend to translate wrongly the structure by using the Future Simple Tense in the target language. This structure is called the normative shall in the language of the law and expresses prescriptiveness of legal rules. For example, although in the Croatian language prescriptiveness is expressed using the Present Tense, regulations of the Constitution of the Republic of Croatia are translated into English using the normative shall: "Members of national minorities shall have equal rights in the Republic

25. The Constitution of the USA, https://bit.ly/39sAAmZ.

26. Mattila, Comparative Legal Linguistics

27. Kordić. Pravna lingvistika. 
of Croatia" (Art. 13. of the Constitution of the Republic of Croatia). Apart from the normative shall, Passive Voice is also frequently used in English legal discourse, while in the Croatian language passive structures are not used so often. A reliable and responsible translator should be aware of these differences between the English language of law and other legal languages.

\section{Nominal Style}

The structure typical of the language of law (not only English) is a polylexical expression consisting of chunks of adjectives and nouns and/or a noun post-modified by another noun, usually in the Genitive case (The Family Law Reform Act, insurance joint-stock company, Justice of the Peace). These structures bring about the complexity of legal texts and are often concerned as the main feature of the legal style - also called 'nominal style'. Trying to avoid ambiguities, lawgivers often build complex sentences containing numerous noun phrases that are often redundant and difficult to understand. This is one of the reasons why legal texts are often criticized by lay people and by linguists. Here is one example of a complex sentence in the Constitution of the USA: "Direct taxes shall be apportioned among the several States which may be included within this Union, according to their respective numbers, which shall be determined by adding to the whole number of free persons, including those bound to service for a term of years and excluding Indians not taxed". ${ }^{28}$

\section{Numerous Types of Legal Texts}

Types and structures of legal texts are culturally bound and strongly influenced by legal systems to which they belong. Thus, it is of utmost importance for a translator to be aware of this fact and to be familiar with the specific structure, terminology, and style used in a specific type of legal text in the target language. Šarčević distinguishes between three groups of legal texts according to their function: a) primarily prescriptive texts, b) descriptive texts including prescriptive parts and c) purely descriptive texts. The first type encompasses statutes and subordinate laws, codifications, treaties and conventions, and contracts. Descriptive texts with prescriptive parts are produced in the courts and include judicial decisions and documents used in judicial proceedings (actions, pleadings, briefs, appeals, requests), while purely descriptive texts include academic textbooks and scholarly articles, as well as legal opinions and commentaries. ${ }^{29}$ The type of the legal text to be translated, along with the purpose of the translation, the target receiver, the source and the target legal systems, and

28. The Constitution of the USA, https://bit.ly/39sAAmZ.

29. Šarčević, New Approach to Legal Translation. 
the rules of law interpretation in those systems, make decisive factors influencing the translation strategy.

\section{Specific Challenges of translating EU Law Texts}

\section{The Role of Translation in a Multilingual European Union}

At the time of political and economic integration, the importance of legal translation has immensely increased. The future functioning of international communities, in this case the European Union will depend a great deal on competent and skilful translators who are able to produce reliable translations with the same legal effect as the source text. Due to the essential importance of multilingual translation for the functioning of the European Union, legal translators are faced with demanding and responsible tasks in their translation activity: "The fact that the parallel texts of legal instruments are usually equally authentic makes it essential for translators to guarantee the reliability of authenticated translations". ${ }^{30}$

Translation of legal texts in the context of EU legislation has been the topic of linguistic research and discussion for several years. Referring to the specific translation procedure in the European Commission, Šarčević states that a more appropriate expression for the procedure would be drafting legal texts than translating legal texts, ${ }^{31}$ while Cosmai argues for the term co-drafting in all EU languages rather than translating into all 24 EU languages. ${ }^{32}$ However, the practice of the translation procedure in DGT (Directorate General for Translation) within the European Commission reveals that the primary EU law documents are at first drafted simultaneously in the three working EU languages - English, French and German, and then translated into all other official languages. In this respect, we can argue that in the EU translation procedure one may speak of the start text rather than the source text. The statistics on the translation activity of the Commission from the year 2012 indicate that $73 \%$ of the documents submitted for translation were drafted in English, 12\% in French and 3\% in German. As for the target languages of translation, the greatest number of legal documents are translated into English $(14.92 \%)$, French $(8.25 \%)$, German $(6.47 \%)$ and the percentage of the texts into the remaining languages ranges from $3.37 \%$ to $4.4 \% .{ }^{33}$ Two essential principles

30. Šarčević, New Approach to Legal Translation, 271.

31. Šarčević, New Approach to Legal Translation.

32. Domenico Cosmai, The Language of Europe. Multilingualism and Translation in the EU Institutions: Practice, Problems and Perspectives (Brussels: Université de Bruxelles, 2014), 42.

33. Cosmai, Language of Europe, 100. 
in co-drafting/translating legal texts are the principle of legal certainty of all language versions and the principle of legal uniformity. The latter principle implies that the entire EU law should be interpreted in the same way across the Union because member states need to adopt a common nomenclature by harmonizing their different legal concepts. For that purpose, the multilingual lexicon of European law has been created and the terminological database of the European Commission (EurLex) has been developed. In such a complex conglomerate of legal materials, languages and translation tools, specific rules and principles must be followed. As the addressees of EU laws are not only legal experts but also average citizens in the EU member states, all the language versions should guarantee legal certainty to all and enable them communication with the EU institutions and courts. Apart from legal certainty and legal uniformity, the third most important principle governing the whole drafting and/or translation procedure is the standardization principle. The standardization relates to terminological, phraseological and graphical equalization of legal texts in all official languages of the EU. This also includes the graphically identical design of the text, the same structure of articles and sections and the same number of sentences and full stops ("the full stop rule") in all language versions. ${ }^{34}$ As opposite to the structural rigidness of the texts and the use of neologisms, syntactic simplification has been recommended by the Joint Practical Guide of the European Commission, ${ }^{35}$ as well as the use of plain English terms and phrases, e.g. the term to fight the fog. The purpose of this formal rigidness is to enable an easier linguistic manipulation of legal texts when amendments and changes are to be introduced. No wonder that the language of EU law, especially of regulations and directives that should be directly implemented in the member states, are often criticized for their extreme textual uniformity and artificially structured sentences. ${ }^{36}$ An EU terminology database has been developed, and the definitions of neologisms are usually offered within the documents in which they occur. The whole codrafting or translation procedure has been supported by IT translation tools and CAT to control and process the multilingual translation. On the other hand, the EU terminology requires constant updating, but this process cannot follow the intense and rapid changes at all levels of the functioning of the EU law so the EURAMIS translation memory has been created and is updated on

34. Anna Trosborg, "Translating Hybrid Political Texts". In Text Typology and Translation, ed. Anna Trosborg, (Amsterdam, Philadelphia, John Benjamins, 1997), 145-158, 152.

35. https://bit.ly/2Sb9vPh.

36. Diana Yankova, "On Some Aspects of Prescriptive Legal Texts in Continental, Common Law and Supranational Jurisdictions" in Curriculum, Multinlingualism and the Law. Language and Law - Studies in Legal Linguistics, ed. Lelija Sočanac, Christopher Goddard, and Ludger Kremer (Zagreb: Globus, 2008), 483-495. 
a daily basis. Constant changes in the EU law and amendments to its primary and secondary legal sources have influenced the use of hypernyms and terms stemming from English and French as the prevailing languages of communication in the EU institutions. These terms are used in the specific EU law meaning, which is in some cases wider or narrower than their original meaning. Although some authors claim that forming hypernyms and coining new words is necessary to meet the requirements for uniformity and legal certainty of all translated/co-drafted versions of EU laws, ${ }^{37} \mathrm{EU}$ institutions are often criticized for introducing words that English native speakers do not recognize as original English terms.

\section{Ambiguous ("Misused") Terms of the EU Law}

Newly coined words or loanwords with different meaning from that used in English dictionaries are present in the English language of the EU law, but also in most languages of EU member states due to the translation process and the standardization of legal concepts and terms across the EU. Jeremy Gardner is one of the authors who have criticized the inconsistent use of English terms in EU texts and the manipulation with English terms contrary to the rules of English grammar. He has taken a further step and made a list of 128 misused terms of the English language in the EU institutions ${ }^{38}$.

“(...) The European institutions have developed a vocabulary that differs from that of any recognised form of English. It includes words that do not exist or are relatively unknown to native English speakers outside the EU institutions and often even to standard spellcheckers/ grammar checkers ('planification', 'to precise' or 'telematics' for example) and words that are used with a meaning, often derived from other languages, that is not usually found in English dictionaries ('coherent' being a case in point). Some words are used with more-or-less correct meaning, but in contexts where they would not be used by native speakers ('homogenise', for example)". ${ }^{39}$

There are linguists and translators who argue that some terms have become so common in the professional communication within EU institutions that they should be used "even if they are wrong". Gardner strongly rejects this idea claiming that it is "remarkably easy to replace unclear and misleading terms with something more sensible and meaningful." 40 Here are some of the misused terms from Gardner's list: action, actor, adequate, agenda, agent, cabinet, citizen, coherent/ coherence, competence, conference, consider as, contradictory procedure, deepen, definel

37. Cosmai, The Language of Europe.

38. Jeremy Gardner, Misused English words and expressions in EU publications (European Court of Auditors, 2016).

39. Gardner, Misused English words, 3.

40. Gardner, Misused English words, 2. 
definition, dispose (of), elaborate, ensure (to), enterprise, establish, eventual/ eventually, expertise, externaliselexternalisation, foresee, formulate, frame, homogenise, important, informatics, intervention, introduce, justify/justification, legislator, modify/modification, note, notify to, operator, orientations, perspective, planification, project, reasonability, responsible, retain, service, shall, so-called, suppress/suppression, third country, transmit, transpose, treatment, visa. Gardner has explained every term in the way it is used in English dictionaries, and then contrasted it with the meaning used in the EU, e.g., 'actor': in EU usage, 'actors' are often simply people who perform actions, or 'the people and/or organisations involved in doing something'. As this meaning is also found in US English, it also occurs in some sectors of international relations." 41

Even superficial analysis of the listed terms shows that most terms are derived from other languages, in most cases Latin and French, and many of them are internationalisms with their own lexical forms in most EU languages. Internationalisms are "words that coincide in their external form (taking into account regular correspondences of sounds with graphic units), fully or partially correspond in meaning, express concepts of international significance, and coexist in various languages, including those that are unrelated or distantly related" ${ }^{\prime \prime}$. In some of the terms listed by Gardner, there are slight differences between the dictionary meaning of an English term and its meaning in the EU texts. An illustration for that may be the adjective adequate: "Adequate is frequently used with the meaning of 'appropriate'. However, its actual meaning is closer to 'satisfactory' or sometimes even 'barely satisfactory'. An 'adequate solution' to a problem may not be the best one, but it will do. An 'appropriate solution' is one that is fitting. Finally, in English, we say that something is 'adequate for' something else, not 'adequate to'." 43 Examples like this can well illustrate the challenges that translators are confronted with in translating English terms with meanings differing from those used in English dictionaries and should be aware of the fact, that only glossaries and lexical database of the European Union should be used as a source in translating legal texts of the EU. Interestingly, some of the EU terms of international meaning in the English language or adaptations of English terms have been used in the Croatian language of public communication more intensely than ever before. They are not only used in political reports or discussions in public media but also have become a part of everyday communication in business or contemporary political events. Some English (or French) loanwords are adapted to Croatian word formation rules, like direktiva (from directive - instead of the Croatian term smjernica), transparentnost (transparency), harmonizacija (harmonization), implementacija, and senzibiliziranje. Some are literally translated and used either in a wrong meaning or as false friends of original English terms.

41. Gardner, Misused English words, 9.

42. The Free Dictionnary. Internationalisms. https://bit.ly/2vjxIKl, accessed on 14 March 2019, 21:39.

43. Gardner, Misused English words, 11. 
For example, the term classified document is translated as klasificirani dokument, although in Croatian klasificirani means sorted into classes; the term legal transaction is translated as transakcija, while in Croatian it has always been a financial term and its Croatian equivalent is pravni posao. Accordingly, the term notificirati parlament was adapted from the English term to notify the Parliament, although the term notificirati does not exist in Croatian. Obviously, political and economic internationalization has also led to the internationalization of legal terms in the EU.

\section{Discussion: Approach to Solving Problems in Legal Translation}

The problems listed above clearly indicate the complexity of skills and competences that legal translators should possess to be able to produce a correct and reliable translation, which preserves legal certainty and produces the same legal effect in the target culture as the source text. According to Šarčević, apart from the knowledge of the source language and the target language and their specific legal terminologies, a legal translator should understand the principles of logic, master logical reasoning and possess a comparative law knowledge. He/she should possess the ability of problem solving, the ability of text analysis and the knowledge of the target legal system and the source legal system. ${ }^{44}$ Pizzuto argues that a legal translator should also master methods and procedures that help him/her in capturing the meaning of the source language and re-expressing that meaning in the target language and target culture. In the legal translation, which is strongly culturally bound, and usually involves different legal concepts and terms in the source and the target language, he recommends the following types of translation techniques: explanatory modulation, adaptation, paraphrasing, concretization or differentiation of terms. ${ }^{45}$

Keeping in mind all the necessary types of knowledge, skills and attitudes, the translator should also use specific translation strategies and take care of the sequence of techniques to be applied in the process of legal translation. In my lectures on legal translation, I have defined this approach as "the approach-fromthe-macro-to-the-micro-level", which includes the following strategies and techniques:

1. The first step should be reading the whole text and determining its main idea, its purpose and the target receiver, as well as the type of legal text to which it belongs.

44. Šarčević, New Approach to Legal Translation, 13-14.

45. Pizzuto, "Translation Procedures". 
2. The next step is embedding the source text and the target text in their corresponding legal and cultural systems ${ }^{46}$. It is essential for a legal translator to know whether the text belonging to the common law system should be translated into the language of the civil law system or some other legal system (e.g. "the hybrid" system of the EU law). Due to the fact, that legal systems differ in their legal concepts and terms, the translator must be aware of the fact that the target language might not dispose of adequate equivalent terms designating those concepts (e.g. law of torts in the common law system and its functional equivalent in the civil law system). If a legal text is to be translated into English, it is of utmost importance whether the target legal system/culture is that of the United Kingdom, the USA or Canada, because of the possible incongruence of legal concepts and terms in the three legal systems. This is especially important in case of the legal system of Canada, which includes elements of the common law and the civil law system.

3. The source text should also be embedded into the branch of law to which it belongs. In this context, the translator should be aware of the specific legal terminology and phraseology within that branch in the source language and the target language. This is extremely important in the cases of internal polysemy, i.e. the cases of using different terms for the same concepts within the same language (f. e. to sue in civil law vs. to prosecute in criminal law). It is useful to create a list of such terms and find their functional equivalents in the target language.

4. A legal translator should always keep in mind specific features of the national legal system of the source language and the differences occurring in the target legal system and culture. Such cultural differences may refer to a different organization of local and regional self-government, different organization, hierarchy and jurisdiction of courts between two systems, different branches of law and their specific terminology in the source and the target legal systems, etc.

5. The translator should be constantly aware of the fact that polysemy, synonymy, antonymy, metaphoric terms and collocations, doublets, illogical expressions, phrasal verbs and specific grammar structures (in the English language of law the normative shall, passive voice, noun phrases, and structures) represent significant features of the language of the law. The translator should try to find the best possible solutions for the translations of those phenomena in the target language in conformity with the target legal system and culture.

6. In translating legal phrases and idioms, several facts should be taken into consideration. Although Latin legal phrases have been used in many legal

46. The term embedding ("Einbettung") is borrowed from the esteemed Austrian expert in translation Erich Prunč 
systems, a translator should be aware that many Latin phrases have evolved differently in different languages and check their meanings and their specific use in the target language/ legal system. Especially idioms need a special approach, e.g. the expression hand to hand combat, not: body to body combat, or the term blood type in English vs. blood group (krona grupa) in Croatian. In such situations, the following translation techniques can be used: explanatory modulation, adaptations, paraphrasing, concretization or differentiation, etc.

7. In the process of translation, the translator should also ensure sources that could help him/her in translation - legal dictionaries, written sources of information or those available online. This particularly refers to the translation of EU laws, when specific vocabulary sources and terminological bases should be used. All available sources used in the translation process to the purpose of a reliable translation are determined in the theory of translation as capital. ${ }^{47}$ In cases of ambiguities, when it is necessary to choose between several possible options of translation, a recommended strategy is to consult a legal expert in the relevant legal field.

\section{Conclusions}

At a time of intensive political and economic integration and cooperation, the importance of legal translation has immensely increased. In this paper, the problems and challenges in translating legal texts are presented and analysed by comparing illustrative examples in English, German and/or Croatian languages. Special attention was paid to specific linguistic phenomena in the English language of the law that represent difficulties for an inexperienced translator, and some solutions were offered on how to approach those translation problems. The work of a translator in the sphere of EU law is considered one of the fundamental activities in the European Union as a complex conglomerate of different nations, cultures, and languages. Introducing new terms into the English language and using the existing ones with a different meaning from that used by native speakers is present not only in the English terminology of the EU, but also in the languages of the member states. Many of those terms are internationalisms with similar lexical structures and the same or similar meaning in most European languages. Usage of neologisms and internationalisms can be observed as the result of internationalization and integration processes in Europe since the first economic integration in 1955. It can also be perceived as the consequence of specific translation procedure carried out in the Directorate General of the European Commission, which is determined as legal drafting in different

47. Prunč, Entwicklungslinien. 
languages rather than legal translation and governed by equalization, harmonization and standardization as basic principles of the EU translation process.

As it has been argued in previous sections of this paper, languages are subject to changes and influenced by other languages, as well as by the reality they reflect. This particularly refers to the languages of the EU, which, as Jose Manuel Barroso, the ex-President of the EU Commission stated, "undergo constant metamorphosis, reflecting the continuous evolution of our political, economic and social spheres." ${ }^{48}$ The example of the Croatian language illustrates that some EU law terms have been accepted and introduced as loanwords or (false) adaptation of English EU terms. On the other hand, the example of Austrian and German laws at the beginning of the $20^{\text {th }}$ century indicates that a concerted action by linguists can lead to some positive (though not substantive) changes in the language of the law. Research findings in the field of legal linguistics indicate that the language of the law is not inclined to changes (archaisms, obscurity, influence of Latin, "wordiness", rituality and redundancy), but the novelties in the new legal system of EU and the specific principles of multilingual translation have obviously influenced linguistic changes in the field of law.

\section{References}

Bhatia, Vijay Kumar, and Bhatia, Aliti. "Legal discourse across cultures and sociopragmatic contexts". World Englishes, 30, no. 4 (2011), 481-495. https://doi.org/ 10.1111/j.1467-971X.2011.01735.

Cosmai, Domenico. The Language of Europe. Multilingualism and Translation in the EU Institutions: Practice, Problems and Perspectives. Brussels: Université de Bruxelles, 2014.

Duranti, Alessandro. Linguistic Antropology. Cambridge: Cambridge University Press, 1997. https://doi.org/10.1017/CBO9780511810190

Gardner, Jeremy. Misused English words and expressions in EU publications. European Court of Auditors. Accessed March 14, 2019. https://bit.ly/2UKWhu2.

Haigh, Rupert. Legal English. Abingdon/New York: Routledge-Cavendish, 2004.

Joint Practical Guide. European Commission. 2013. Accessed March 25, 2019. https://bit.ly/2uBaHCm

Kelly, Dorothy. A Handbook for Translator Trainers. Manchester: St Jerome, 2005.

Kordić, Ljubica. Pravna lingvistika - sinergija jezika i prava/Legal Linguistics-A Synergy of Language and the Law/. Osijek: Pravni fakultet Osijek, 2015.

Lerch, Kent. Recht verstehen. Verständlichkeit, Missverständlichkeit und Unverständlichkeit von Recht. Berlin/New York: de Gruyter, 2005.

48. Cosmai, Language of Europe, 7. 
L'Homme, Marie-Claud and Bertrand, Claudine. "Specialized Lexical Combinations: Should they be described as Collocations or in Terms of Selectional Restrictions?" In Proceedings. Ninth Euralex International Congress, 497-506. Stuttgart: Stuttgart University, 2000.

Mattila, Heikke. Comparative Legal Linguistics. Aldershot: Ashgate Publishing, 2006.

Pizzuto, Angelo. "Translation Procedures: The Technical Component of the Translation Process". Accessed March 25, 2019. https://bit.ly/2tKENTN.

Prunč, Erich. Entwicklungslinien der Translationswissenschaft. Von den Asymmetrien der Sprachen zu den Asymmetrien der Macht. Berlin: Frank \& Timme, 2012.

Reiss, Katarina and Vermeer, Hans. Grundlegung einer allgemeinen Translationstheorie. Tübingen: Niemeyer, 1984.

Sandrini, Peter. (Ed). Ubersetzen von Rechtstexten-Fachkommunikation im Spannungsfeld zwischen Rechtsordnung und Sprache. Tübingen: Gunter Narr Verlag, 1999.

Sandrini, Peter. Der transkulturelle Vergleich von Rechtsbegriffen. In Legal Language in Action: Translation, Terminology, Drafting and Procedural Issues, edited by Šarčević, Susan, Sočanac, Lelija, 151-167. Zagreb: Globus, 2009.

Šarčević, Susan. New Approach to Legal Translation. The Hague-London-Boston: Kluwer Law International, 2000.

Šarčević, Susan. Legal Language in Action: Translation, Terminology, Drafting and Procedural Issues. Zagreb: Globus, 2009.

The Free Dictionnary. Internationalisms. Accessed March 14, 2019. https://bit.ly/2v jxIK1.

The Constitution of the U.S.A. Accessed March 14, 2019. https://bit.ly/31EgweF.

Tiersma, M. Peter. Legal Language. Chicago, IL: University of Chicago Press, 1999.

Trask, Robert L. Language and Linguistics: The Key Concepts. New York: Routledge, 2008.

Trosborg, Anna. "Translating Hybrid Political Texts". In Text Typology and Translation, 145-158 edited by Trosborg, Anna, Amsterdam, Philadelphia: John Benjamins, 1997. https://doi.org/10.1075/btl.26

Yankova, Diana. “On Some Aspects of Prescriptive Legal Texts in Continental, Common Law and Supranational Jurisdictions". In Curriculum, Multinlingualism and the Law. Language and Law - Studies in Legal Linguistics, edited by Sočanac, Lelija, Goddard, Christopher and Kremer, Ludger, 483-495. Zagreb: Globus, Zagreb, 2008.

Zweigert, Konrad, Kötz, Hein. Einführung in die Rechtsvergleichung [An Introduction to Comparative Law], $1^{\text {st }}$ ed., 1996. 
